\title{
A NOVEL PHENYLALANINE AMMONIA-LYASE FROM KANGIELLA KOREENSIS
}

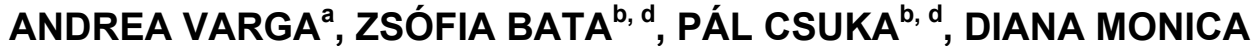 \\ BORDEA $^{\mathrm{a}}$, BEÁTA G. VÉRTESSY ${ }^{\mathrm{c}, \mathrm{d}}$, ADRIANA MARCOVICl ${ }^{\mathrm{e}}, \mathrm{FLORIN}^{\circ}$ \\ DAN IRIMIE ${ }^{a}$, LÁSZLÓ POPPE ${ }^{*}$ a, b, LÁSZLÓ CSABA BENCZE ${ }^{*}$
}

\begin{abstract}
This study describes the cloning of the gene encoding a novel phenylalanine ammonia-lyase from Kangiella koreensis (KkPAL) into pET19b expression vector. Optimization of protein expression and purification conditions yielded $15 \mathrm{mg}$ pure soluble protein from one liter of $E$. coli culture. Enzymatic activity measurements of the ammonia elimination reaction from different natural aromatic amino acids proved the protein to be a phenylalanine ammonia-lyase. The isolated protein showed remarkably high, $81.7^{\circ} \mathrm{C}$ melting temperature, making it especially suitable for biocatalytic applications.
\end{abstract}

Keywords: phenylalanine ammonia-lyase, Kangiella koreensis, protein expression, optimization

\section{INTRODUCTION}

The use of enzymes as biocatalysts for the preparation of chemicals has received steadily increasing attention over the past few years and found significant applications in many areas, especially in the synthesis of

a Babeş-Bolyai University, Faculty of Chemistry and Chemical Engineering, Arany János str. 11, RO-400028, Cluj-Napoca, Romania.

${ }^{b}$ Department of Organic Chemistry and Technology, Budapest University of Technology and Economics, Müegyetem rkp. 3, H-1111 Budapest, Hungary.

${ }^{c}$ Department of Biotechnology and Food Sciences, Budapest University of Technology and Economics, Szt. Gellért tér 4, H-1111 Budapest, Hungary.

${ }^{d}$ Institute of Enzymology, Research Centre for Natural Sciences of Hungarian Academy of Sciences, Magyar tudósok körútja 2, H-1117 Budapest, Hungary.

e Clinical, Pharmacology and Pharmacokinetics Department, Terapia SA, Fabricii str. 124, RO-400632 Cluj-Napoca, Romania.

*Corresponding authors: cslbencze@chem.ubbcluj.ro; poppe@mail.bme.hu; 
A. VARGA, Z. BATA, P. CSUKA, D. M. BORDEA, B. G. VÉRTESSY, A. MARCOVICI, F. D. IRIMIE,

L. POPPE, L. C. BENCZE

pharmaceutical and fine chemical targets. [1] Microbial sources received significant attention in the development of enzymes for research or industrial purposes, as microbes can be produced economically in short fermentation time and using inexpensive media. [2]

The natural role of phenylalanine ammonia-lyases (PALs) is the catalysis of non-oxidative ammonia elimination from L-phenylalanine ( $L$ Phe), to form (E)-cinnamic acid,[3] as part of the phenylpropanoid synthesis pathway in case of plants, and to form secondary metabolites in fungi and bacteria. [4] Structurally, PALs resemble to phenylalanine 2,3-aminomutases (PAMs),[5] tyrosine 2,3-aminomutases (TAMs),[6] tyrosine ammonia-lyases (TALs),[7] and histidine ammonia-lyases (HALs). [8] All of these enzymes rely on the protein-derived electrophilic prosthetic group, 3,5-dihydro-4methylidene- $5 \mathrm{H}$-imidazol-5-one (MIO), that forms autocatalytically from an XSG triade which contains usually Ala-Ser-Gly active site residues. [9]

Synthetic applications are based mostly on the reverse reaction of PAL, as the stereoselective ammonia addition results in the formation of enantiopure unnatural L-amino acids from the corresponding arylacrylates. [10] However, PALs as biocatalysts in these reactions must withstand as high as $6 \mathrm{M}$ ammonia concentrations to achieve high conversions. PALs of marine origin - especially PAL from Idomarina loihiensis (IIPAL) - were capable of catalyzing the ammonia addition with high activity at elevated ammonia and substrate concentrations. [11] Alternatively, enzyme immobilization proved to be a successful strategy for prolonging the lifetime of PALs as biocatalysts. [12]

In frame of our general interest to clone thermotolerant and stable PALs as efficient biocatalysts focusing on enzymes of marine and extremophile origin, herein we describe the molecular cloning, expression and purification of a novel PAL from a marine bacterium Kangiella koreensis (KkPAL). [13]

\section{RESULTS AND DISCUSSION}

\section{Identification of KkPAL}

Prokaryotic MIO enzymes are about 150-200 residues shorter than the MIO enzymes from eukaryotes, as the eukaryotic ones contain an additional shielding domain at their C-terminus (Table 1). The shorter bacterial enzymes tend to be more stable than the ones of eukaryotic origin. 
Table 1. Comparison of six typical MIO enzymes.

\begin{tabular}{lccc}
\hline & Uniprot code & Seq. length & Seq. identity [14] \\
\hline Kangiella koreensis PAL & C7R9W9 & 516 & $100 \%$ \\
Idomarina loihiensis PAL & Q5QXE5 & 515 & $66 \%$ \\
Anabaena variabilis PAL & Q3M5Z3 & 567 & $28 \%$ \\
Petroselinum crispum PAL & P24481 & 716 & $22 \%$ \\
Rhodobacter sphaeroides TAL & Q3IWB0 & 523 & $29 \%$ \\
Pseudomonas putida HAL & P21310 & 510 & $27 \%$ \\
\hline
\end{tabular}

Proteins encoded in extremophile organisms, similarly to their host organisms, are adopted to their living conditions. Thus, enzymes isolated from thermophilic or marine organisms are expected to function efficiently at high temperatures and salt concentrations, respectively. A recently identified PAL from Idomarina loihiensis (IIPAL) [15] showed promising results in the production of optically active phenylalanine derivatives. [11] A bioinformatics based search using Blastp in the $\mathrm{NCBI}$ Non-redundant protein sequence database identified the KKPAL sequence to be $66 \%$ identical to IIPAL (Table 1). Thus, it was expected that KkPAL could be a stable and efficient biocatalyst for the synthesis of optically active phenylalanine analogues.

Comparison of the active site residues of KkPAL with IIPAL and two further MIO enzymes (Table 2) showed that all catalytic residues and residues in the carboxylate binding region of the active site were conserved. However, the aromatic binding region of the active site of $K k P A L$ appeared to be different, as at position 90 in KKPAL, a histidine was found instead of leucine within the mesophilic PALs (AvPAL and PCPAL). Automated annotation of the sequence database assigned HAL function to the KkPAL sequence due to the characteristic histidine residue at position 90. However, phenylalanine at position 89 renders the aromatic binding pocket of the active site more "PAL-like" (Table 2). Based on sequence similarity, we hypothesized that amongst the natural aromatic amino acids, this enzyme will be the most active in the ammonia elimination reaction from phenylalanine.

Histidine to phenylalanine mutations of the adjacent residue (residue 89 in Table 2.) enhanced the PAL activity of the tyrosine ammonia-lyase from Rhodobacter sphaeroides (RsTAL), and decreased significantly the TAL activity. [16] The presence of a hydrogen bond forming residue, histidine at the aromatic binding pocket of KkPAL suggested a possible tyrosine ammonia-lyase activity and probable substrate promiscuity towards other natural aromatic amino acids. 
A. VARGA, Z. BATA, P. CSUKA, D. M. BORDEA, B. G. VÉRTESSY, A. MARCOVICI, F. D. IRIMIE, L. POPPE, L. C. BENCZE

Table 2. Sequence alignment of active site residues ${ }^{a}$ in six typical MIO enzymes

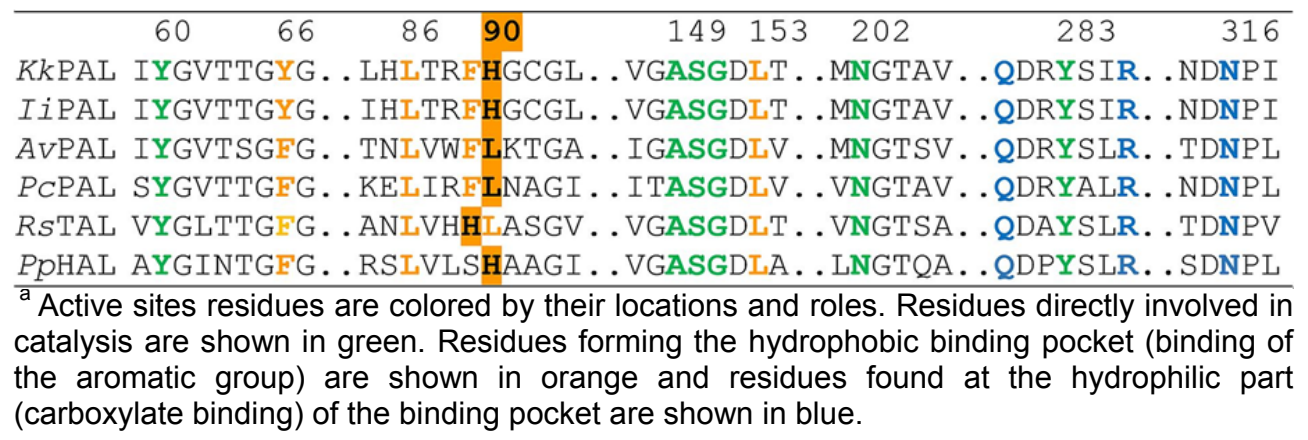

\section{Molecular cloning of KkPAL}

The gene encoding KkPAL was codon optimized for better expression in $E$. coli and synthesized. The synthetic KkPAL gene was cloned in pUC57 production vector and later sub-cloned into the pET19b expression vector. Restriction sites for $\mathrm{Ndel}, \mathrm{Ncol}$ and $\mathrm{BamHI}$ were added to the protein coding sequence allowing directional cloning into the expression vector. Primers detailed in Table 3 (KkPAL_forward and KkPAL_reverse primers) were used to amplify the synthetic gene from the pUC57 cloning vector, followed by restriction cloning to the expression vector using $\mathrm{Ndel}$ and $\mathrm{BamHI}$ enzymes and T4 DNA ligase. The pET19b vector contains an $\mathrm{N}$-terminal $\mathrm{His}_{10}$-tag attached through enterokinase cleavage site to the inserted sequence, facilitating protein purification.

Table 3. Primers used for amplification of KkPAL gene and for the colony PCR

\begin{tabular}{llc}
\hline \multicolumn{1}{c}{ Primers } & \multicolumn{1}{c}{ Sequences } & $\mathbf{T}_{\mathbf{m}}\left({ }^{\circ} \mathbf{C}\right)$ \\
\hline KkPAL_forward primer & 5'CTAGATAATACCATGGGCCATATG3' & 62 \\
KkPAL_reverse primer & 5'CCGATTATGGATCCTTAGTTAGC3' & 62 \\
T7-promoter_forward primer & 5'AATACGACTCACTATAGGGGAATTG3' & 54 \\
T7-terminator_reverse primer & 5'TGCTAGTTATTGCTCAGCGG3' & 55 \\
\hline
\end{tabular}

Colony PCR verified the successful insertion of the DNA encoding KkPAL to the pET19b vector. This convenient high-throughput method determines the presence or absence of the inserted DNA sequence by a standard PCR process, from individual colonies obtained after the ligation reaction. Vector specific T7-promoter forward and T7-terminator reverse oligonucleotides (Table 3 ) served as primers for the PCR reactions. Sequencing of plasmid DNA, isolated from the colonies with positive colony $\mathrm{PCR}$ reactions, ascertained the cloning results. 


\section{Optimization of the overexpression of KkPAL}

Variation of the host cell strain, growth temperature and inducer concentration influence the overexpression levels of the target protein. Strategy for optimization and the identified optimal conditions for KkPAL overexpression are detailed in the next section.

$E$. coli is the most commonly used bacterial host for recombinant protein production. It has become the most popular expression platform, as it is easy to manipulate genetically, inexpensive to culture, and its expression is rapid. [17] E. coli strain Rosetta(DE3)pLysS enables low background expression, and expresses T7 lysozyme suppressing basal T7 RNA polymerase expression, reducing translation of the pET recombinants in the absence of inducer. Hence, we choose Rosetta(DE3)pLysS as host strain for expression of KkPAL.

\section{Optimization of the inducer concentration}

Induction of the lac promoter expresses the target genes in $\mathrm{pET}$ systems. Naturally, this promoter is induced by the lactose metabolite allolactose. However, in practice the non-degradable IPTG (isopropyl $\beta$-D1-thiogalactopyranoside) is employed, instead of lactose. Varying the concentration of IPTG regulates the expression of the target protein. Lowering the IPTG concentration may reduce the protein expression level, thereby increasing the solubility of aggregation prone protein. Although at the cost of increased expression time and lower protein yield. [18]

Protein expression levels of recombinant KkPAL as a function of various inducer concentrations were evaluated in liquid cultures. Upon achieving exponential growth phase (OD at $600 \mathrm{~nm} \sim 0.6)$, cultures were induced with five different concentrations of IPTG between $0 \mathrm{mM}$ and 0.5 $\mathrm{mM}$ and expression proceeded for $3 \mathrm{~h}$ at $37{ }^{\circ} \mathrm{C}$ (Figure 1). KkPAL expression occurred already at $0.1 \mathrm{mM}$ IPTG (60 kDa band Lane 3), and inducer concentration above $0.1 \mathrm{mM}$ enhanced $\mathrm{KkPAL}$ production (Lanes 4-6). However, further increase of the IPTG concentration above $0.2 \mathrm{mM}$ (Lane 4) did not increase KkPAL expression (Lanes 5,6). As later experiments showed, the protein expressed in a soluble form, therefore the IPTG concentration was set to $0.2 \mathrm{mM}$.

\section{Effect of expression temperature on the overexpression of KKPAL}

The optimum temperature for $E$. coli growth is $37^{\circ} \mathrm{C}$, and several studies reported $37^{\circ} \mathrm{C}$ as the best temperature for maximum protein production as well. [19] On the other hand, other studies showed that not 
only the rate of expression, but the culturing temperature affects the proper folding of recombinant proteins. [20] Lowering the expression temperature leads to slower growth of bacteria and reduces the rate of protein production, hence decreasing the risk of aggregation of target protein. In addition, most of the proteases express much less activity at lower temperatures. Thus, degradation of the target proteins at lower temperatures are much less pronounced. [21,22]

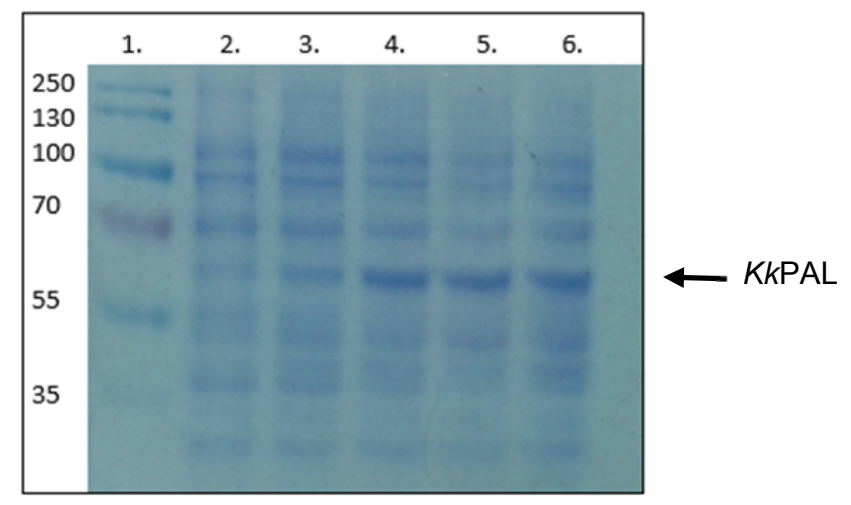

Figure 1. SDS-PAGE showing the effect of various IPTG concentrations on the expression of $K k P A L$ (after $4 \mathrm{~h}$ at $37^{\circ} \mathrm{C}$ ). Samples in the lanes: 1: protein ladder, 2: control (0 mM IPTG), 3: induction with $0.1 \mathrm{mM} \mathrm{IPTG,} \mathrm{4:} \mathrm{induction} \mathrm{with} 0.2 \mathrm{mM}$

IPTG, 5: induction with $0.3 \mathrm{mM} I P T G, 6$ : induction with $0.5 \mathrm{mM}$ IPTG.

Intermittent optical densitometry (OD) measurements at $600 \mathrm{~nm}$ evaluated the effect of growth temperature on the expression of $K k P A L$ after induction. Initially, the cell cultures were incubated at $37^{\circ} \mathrm{C}$. After the density of cells reached $\mathrm{OD}_{600} \sim 0.4$ (approx. 2-3 h), the temperature was reduced (to 20 , 25 or $30^{\circ} \mathrm{C}$ ). To allow cultures to adjust to the temperature change, protein production was only induced 30 minutes after decreasing the temperatures. The density of the cells was monitored as a function of time (Figure 2).

Due to the reduced incubation temperature, the protein synthesis rate was slower at $20{ }^{\circ} \mathrm{C}$ than at 25 or $30{ }^{\circ} \mathrm{C}$ and longer induction times were necessary for cells growth. At higher expression temperatures (25 or $30^{\circ} \mathrm{C}$ ), the protein synthesis was faster and the stationary phase was reached after $8 \mathrm{~h}$, compared to $14 \mathrm{~h}$ at $20^{\circ} \mathrm{C}$. After post-induction, the cells were harvested by centrifugation, followed by sonication and the crude protein mixture in the lysate was purified by metal affinity chromatography on Ni-NTA resin. The maximum yield, $15 \mathrm{mg} \mathrm{L}^{-1}$ purified enzyme, was obtained at $25^{\circ} \mathrm{C}$ expression temperature. The optimal post-induction time on the expression of KkPAL was 12-14 h. 


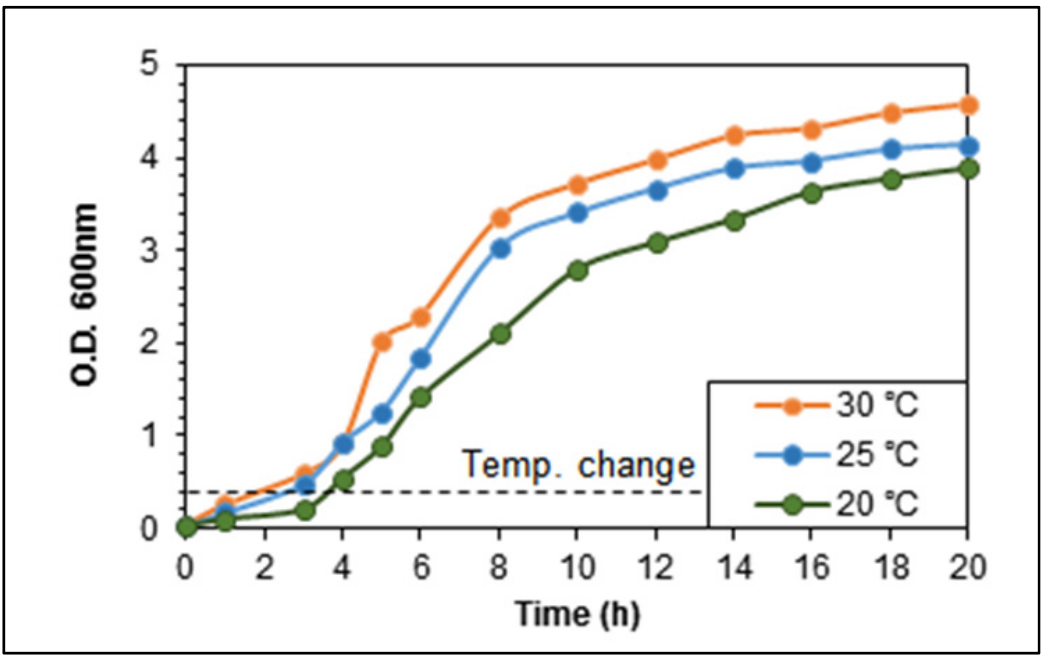

Figure 2. Growth curves of $E$. coli Rosetta(DE3)pLysS containing the pET19bKkPAL plasmid, at 20,25 and $30^{\circ} \mathrm{C}$ in LB medium.

\section{Purification}

\section{Purification using Ni-NTA chromatography}

Ni-NTA chromatography is a rapid and easy purification technique for recombinant proteins carrying a His-tag at either the $\mathrm{N}$ - or $\mathrm{C}$-terminus. The $\mathrm{N}$ atoms of the imidazole rings of the His-tag residues form complexes with the unoccupied coordination sites of the immobilized nickel ions. [23]

In the pET19b vector, a His ${ }_{10}$-tag at the $\mathrm{N}$-terminus is fused to the target proteins, which is longer than the usual $\mathrm{His}_{6}$-tag. Lengthening the His-tag increases the affinity of the enzyme to the Ni-NTA resin. Consequently, higher imidazole concentrations were required to elute the bounded enzyme from the resin (from $250 \mathrm{mM}$ up to $500 \mathrm{mM}$ ). [24] We observed, that KkPAL activity decreased after elution from the Ni-NTA column probably due to prolonged exposure to high imidazole concentration. In order to eliminate this effect, we tested 250, 350, 450, 500 $\mathrm{mM}$ imidazole concentrations for protein elution. The best result was obtained by elution with $350 \mathrm{mM}$ imidazole, resulting in a protein solution which gave a single band on the SDS-PAGE (Figure 3, Lane 2), indicating high purity of the target enzyme. 
A. VARGA, Z. BATA, P. CSUKA, D. M. BORDEA, B. G. VÉRTESSY, A. MARCOVICI, F. D. IRIMIE, L. POPPE, L. C. BENCZE

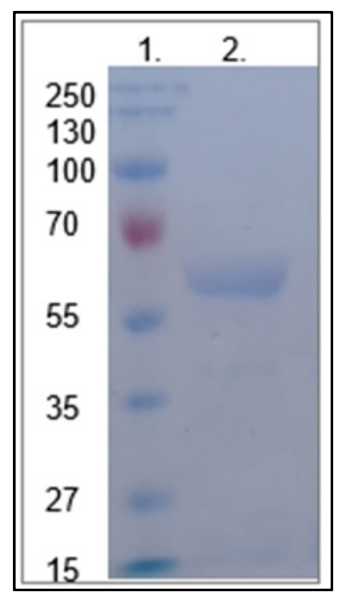

Figure 3. Purification of KkPAL with Ni-NTA chromatography. Lane 1: protein ladder, Lane 2: fraction eluted from Ni-NTA with $350 \mathrm{mM}$ imidazole. Samples were prepared as described in the experimental section.

\section{Characterization of KkPAL}

\section{Enzyme activity measurements}

PAL activity was assayed both in the ammonia elimination and in the ammonia addition reactions. The enzyme activity in the ammonia elimination reaction was determined spectrophotometrically by monitoring the formation of (E)-cinnamic acid. Conversions after $16 \mathrm{~h}$ obtained by HPLC analysis characterize the enzyme activity in the ammonia addition reaction. [25] In Table 4 the specific activity and the conversion of the reaction catalyzed by KkPAL were compared with the corresponding properties of the well-studied PCPAL. Contrary to our expectations, PCPAL had better catalytic activity in the addition as well as in the elimination reactions.

Table 4. Specific activities in the ammonia elimination and the conversion in the addition reactions measured for KkPAL and PCPAL.

\begin{tabular}{|c|c|c|}
\hline & Elimination reaction & Addition reaction \\
\hline Enzyme & $\begin{array}{l}\text { Specific activity }{ }^{\text {a }} \\
{\left[\mu \mathrm{mol} \mathrm{min} \mathrm{mg}^{-1}\right]}\end{array}$ & $\begin{array}{c}\text { Conversion }^{\mathrm{b}} \\
{[\%]}\end{array}$ \\
\hline KkPAL & 0.063 & 3.9 \\
\hline PcPAL & 1.08 & 77.2 \\
\hline
\end{tabular}


KkPAL catalyzed ammonia elimination also from L-tyrosine, however at a slower rate compared to phenylalanine. The spectrophotometric assays could not detect ammonia elimination from histidine and tryptophan, corroborating with the sequence based annotation of the protein as phenylalanine ammonia-lyase.

\section{Thermal stability}

The nanoDSF differential scanning fluorimetry technique is able to analyze the conformational stability and colloidal stability (aggregation behavior) of proteins under different thermal and chemical conditions. The conformational stability of a protein is described by the unfolding transition midpoint $\mathrm{T}_{\mathrm{m}}\left({ }^{\circ} \mathrm{C}\right)$, which is the point at which half of the protein is unfolded. The truly label-free nanoDSF method monitors the intrinsic fluorescence of tryptophans in proteins, which relies on the close surrounding of the given tryptophan and changes upon thermal unfolding. Maximum values in the change of the first derivate of the fluorescent signal define the melting temperature of the protein.

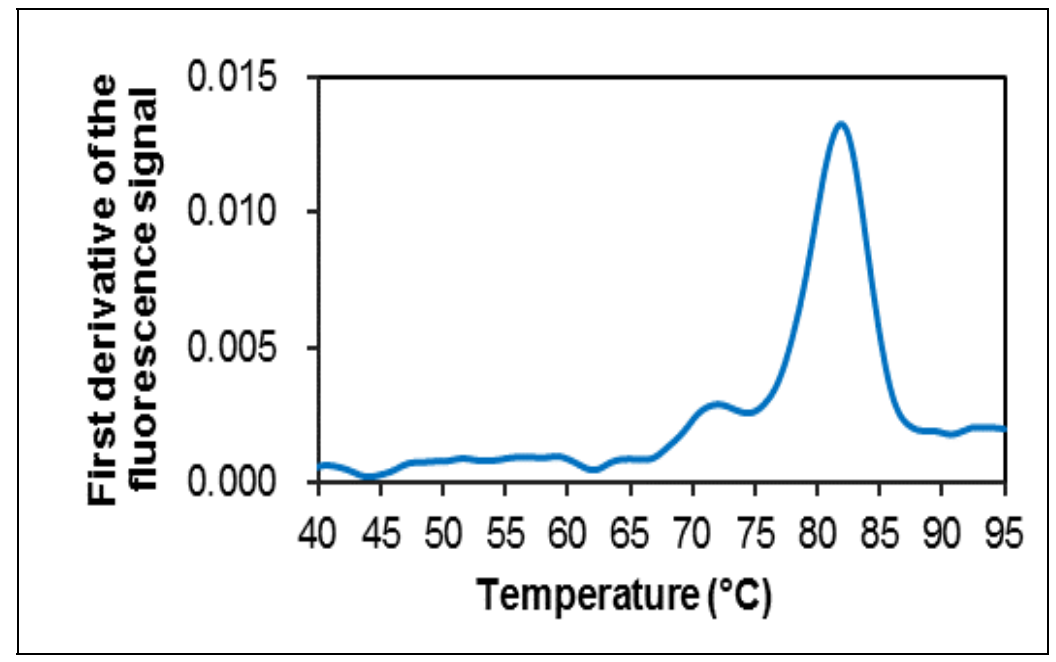

Figure 4. Thermal unfolding curve of KkPAL obtained by nanoDSF measurement

The KKPAL exhibited outstanding thermal stability, as its melting temperature was $81.7^{\circ} \mathrm{C}$ (Figure 4). This melting temperature is $10^{\circ} \mathrm{C}$ higher than that of the eukaryotic PCPAL, $71^{\circ} \mathrm{C}$. 
A. VARGA, Z. BATA, P. CSUKA, D. M. BORDEA, B. G. VÉRTESSY, A. MARCOVICI, F. D. IRIMIE,

L. POPPE, L. C. BENCZE

\section{CONCLUSIONS}

Different experimental conditions were examined for the expression and purification of KkPAL in order to obtain the enzyme in high yield and high purity. After optimization of IPTG concentration, post-induction temperature on the expression and the imidazole concentration in the purification steps, $15 \mathrm{mg} \mathrm{L}^{-1}$ of high purity protein was obtained. For production of KkPAL the induction level with an IPTG concentration of 0.2 $\mathrm{mM}$ was sufficient, followed by $12-14 \mathrm{~h}$ post-induction incubation at $25^{\circ} \mathrm{C}$. During the purification of the $\mathrm{His}_{10^{-}}$tagged protein on Ni-NTA column, a reduction of the imidazole concentration from $500 \mathrm{mM}$ to $350 \mathrm{mM}$ improved the stability of the resulted enzyme.

Activity measurements showed that the newly cloned KkPAL was less active in the ammonia elimination and addition reactions than the most frequently used PcPAL, but the melting temperature of this novel PAL from a marine bacterium exceeded that of the eukaryotic protein by about $10 \mathrm{C}$.

The hydrophobic binding pocket KkPAL, similarly to IIPAL is a hybrid between the typical motifs found in TALs and HALs. In agreement with our sequence-based annotation, KKPAL showed the highest activity towards phenylalanine amongst the aromatic amino acids. Nevertheless, residue patterns at the hydrophobic region of the binding pocket and the recently reported F137V PCPAL with expanded substrate range,[26] suggest that site directed mutagenesis could enhance activity towards other aromatic amino acids.

\section{EXPERIMENTAL SECTION} specified.

All reagents were purchased from Sigma-Aldrich, unless otherwise

\section{Synthesis and cloning of KkPAL gene}

The gene of the Kangiella koreensis PAL (Uniprot code: C7R9W9, encoding $735 \mathrm{AA}$ - Table 5) was optimized to the codone usage of $E$. coli. The 1538 bp long synthetic gene was produced by Genscript in pUC57 vector. At the end of the gene, restriction sites of $\mathrm{Ndel}, \mathrm{Ncol}$ and $\mathrm{BamHI}$ restriction enzymes were introduced for directional cloning into the $\mathrm{pET} 19 \mathrm{~b}$ expression vector (Figure 5). 
Table 5. Amino acid and DNA sequences of recombinant wt-KkPAL

\section{Amino acid sequence of $\mathrm{KkPAL}$ \\ Nucleotide sequence of the gene}

MTDTKTNITFGHSSLTIEQICQLAKC NATAKLNSAPEFKHKIDQGADFIKEI LREDGVIYGVTTGYGDSVTTPVPVQD THELPLHLTRFHGCGLGSIFSAEHTR AILATRLASLSQGYSGVSWSLLQQLE LLLQKDILPRIPEEGSVGASGDLTPI SYVAAALIGEREVLYKGQTQPTEQVF KSLGIKPITLQPKEGLAIMNGTAVM ALACLAFQRADYLTQLCSRITSLCSI ALQGNSAHFDELLFSVKPHPGQNQVA AWIRDDLNHYKHPRNSDRLQDRYSIR CAPHIIGALKDAMPWMRQTIETELNS ANDNPIIDGAGQHVLHGGHFYGGHIA MVMDSMKTGIANLADLMDRQMALLVD SKENNGLPNNLSAASEORRPLNHGFK AVQIGVSAWTAEALKLTMPASVFSRS TECHNQDKVSMGTIAARDCLRILDLT EQVAAASLMAATQAVTLRIKQSQLDK SSLSDGVLSTLEQVFEHFELVSEDRP LEHELRHFVALIQEQHWSTYAN
5' AATACCATGGGCCATATGATGACCGACACCAAAACCAACATCACCTTCGGTCACTCTTCTCTGACCA TCGAACAGATCTGCCAGCTGGCTAAAGGTAACGCTACCGCTAAACTGAACTCTGCTCCGGAATTTAAAC ACAAAATCGACCAGGGTGCTGACTTCATCAAAGAACTGCTGCGTGAAGACGGTGTTATCTACGGTGTTA CCACCGGTTACGGTGACTCTGTTACCACCCCGGTTCCGGTTCAGGACACCCACGAACTGCCGCTGCACC TGACCCGTTTCCACGGTTGCGGTCTGGGTTCTATCTTCTCTGCTGAACACACCCGTGCTATCCTGGCTA CCCGTCTGGCTTCTCTGTCTCAGGGTTACTCTGGTGTTTCTTGGTCTCTGCTGCAGCAGCTGGAACTGC TGCTGCAGAAAGACATCCTGCCGCGTATCCCGGAAGAAGGTTCTGTTGGTGCTTCTGGTGACCTGACCC CGCTGTCTTACGTTGCTGCTGCTCTGATCGGTGAACGTGAAGTTCTGTACAAAGGTCAGACCCAGCCGA CCGAACAGGTTTTCAAATCTCTGGGTATCAAACCGATCACCCTGCAGCCGAAAGAAGGTCTGGCTATCA TGAACGGTACGGCTGTTATGACCGCTCTGGCTTGCCTGGCTTTCCAGCGTGCTGACTACCTGACCCAGC TGTGCTCTCGTATCACCTCTCTGTGCTCTATCGCTCTGCAGGGTAACTCTGCTCACTTCGACGAACTGC TGTTCTCTGTTAAACCGCACCCGGGTCAGAACCAGGTTGCTGCTTGGATTCGTGACGACCTGAACCACT ACAAACACCCGCGTAACTCTGACCGTCTGCAGGACCGTTACTCTATCCGTTGCGCTCCGCACATCATCG GTGCTCTGAAAGACGCTATGCCGTGGATGCGTCAGACCATCGAAACCGAACTGAACTCTGCTAACGACA ACCCGATCATCGACGGTGCTGGTCAGCACGTTCTGCACGGTGGTCACTTCTACGGTGGTCACATCGCTA TGGTTATGGACTCTATGAAAACCGGTATCGCTAACCTGGCTGACCTGATGGACCGTCAGATGGCTCTGC TGGTTGACTCTAAATTCAACAACGGTCTGCCGAACAACCTGTCTGCTGCTTCTGAACAGCGTCGTCCGC TGAACCACGGTTTCAAAGCTGTTCAGATCGGTGTTTCTGCTTGGACCGCTGAAGCTCTGAAACTGACCA TGCCGGCTTCTGTTTTCTCTCGTTCTACCGAATGCCACAACCAGGACAAAGTTTCTATGGGTACGATCG CTGCTCGTGACTGCCTGCGTATCCTGGACCTGACCGAACAGGTTGCTGCTGCTTCTCTGATGGCTGCTA CCCAGGCTGTTACCCTGCGTATCAAACAGTCTCAGCTGGACAAATCTTCTCTGTCTGACGGTGTTCTGT CTACCCTGGAACAGGTTTTCGAACACTTCGAACTGGTTTCTGAAGACCGTCCGCTGGAACACGAACTGC GTCACTTCGTTGCTCTGATCCAGGAACAGCACTGGTCTACCTACGCTAACTAAGGATCCATA 3'

Cleavage sites of the restriction enzymes: Ncol :CCATGG, Ndel :CATATG, BamHI: GGATCC

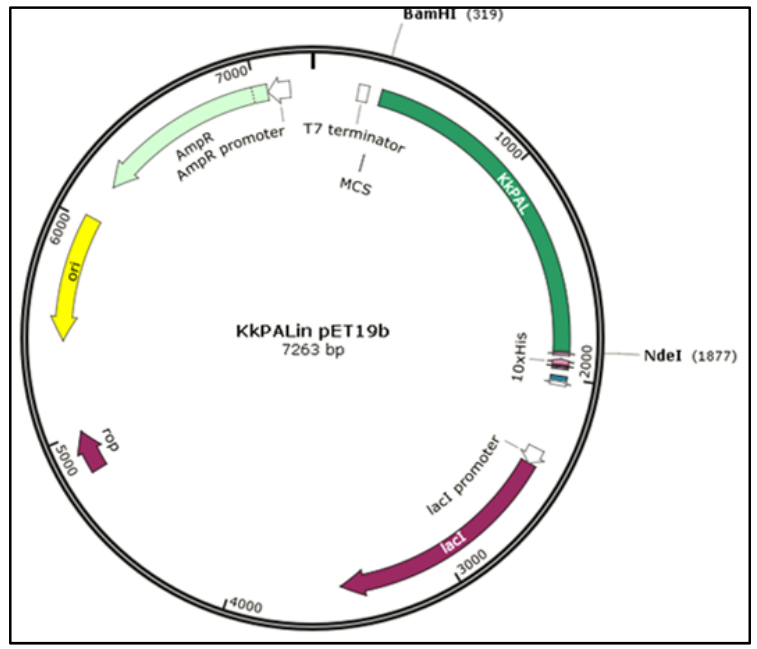

Figure 5. Vector map of the pET19b-KkPAL construct. 
A. VARGA, Z. BATA, P. CSUKA, D. M. BORDEA, B. G. VÉRTESSY, A. MARCOVICI, F. D. IRIMIE, L. POPPE, L. C. BENCZE

\section{PCR reaction for amplification of the gene}

The PCR reactions with a total volume of $50 \mu \mathrm{L}$ consisted of $90 \mathrm{ng}$ of DNA template (plasmid containing the gene of $K k P A L), 1 \mu \mathrm{M}$ of each of the primers, $200 \mu \mathrm{M}$ dNTP (ThermoFischer) and 2.5 units of Phu Hot-Start DNA polymerase (ThermoFischer). The PCR cycles were initiated at $95^{\circ} \mathrm{C}$ for 3 min to denature the template DNA, followed by 35 amplification cycles $\left(95^{\circ} \mathrm{C}\right.$ for $30 \mathrm{~s}, 57{ }^{\circ} \mathrm{C}$ for $30 \mathrm{~s}$ and $72{ }^{\circ} \mathrm{C}$ for $3 \mathrm{~min}$ ). The PCR cycles were finished with a final extension step at $72{ }^{\circ} \mathrm{C}$ for $15 \mathrm{~min}$.

The PCR products were further purified, using the DNA Clean \& Concentrator ${ }^{\mathrm{TM}}-25 \mathrm{Kit}$, by Zymo research. The purified PCR products and the recipient circular pET19b vector were digested with $\mathrm{Ndel}$ and $\mathrm{BamHI}$ restriction enzymes (ThermoFischer), at $37^{\circ} \mathrm{C}$ for $1 \mathrm{~h}$ and then $40 \mu \mathrm{L}$ (approx. $2 \mu \mathrm{g}$ ) of each digested DNA was purified by agarose gel electrophoresis. The DNA bands were cut out from the agarose gel. The recipient plasmid and insert at a molar ratio 1:3 were co-extracted using Gen Elute Gel Extraction Kit (Genomed) and afterwards ligated in presence of T4 DNA ligase (ThermoFischer) at $22^{\circ} \mathrm{C}$ for $1 \mathrm{~h}$.

\section{Transformation in E. coli cells}

For the transformation of plasmid DNA into $E$. coli XL1-Blue (for plasmid amplification) and Rosetta(DE3)pLysS (for expression) the heat shock method was used. Thawing the chemically competent bacterial cells $(50 \mu \mathrm{L})$ on ice for $15 \mathrm{~min}, 1-2 \mu \mathrm{L}$ of plasmid DNA was added followed by incubation for $20 \mathrm{~min}$ on ice. The heat shock was performed by incubating the sample at $42^{\circ} \mathrm{C}$ for $45 \mathrm{~s}$, and on ice for further $2 \mathrm{~min} .400$ $\mu \mathrm{L} L B$ media was added and the cells were grown at $37 \mathrm{C}$ for $1 \mathrm{~h}$. In case of XL1-Blue transformation the transformed bacteria were plated on LB agar-plates containing tetracycline $\left(30 \mu \mathrm{g} \mathrm{mL}^{-1}\right)$ and carbenicilin $(50 \mu \mathrm{g}$ $\mathrm{mL}^{-1}$ ). In case of Rosetta(DE3)pLysS transformation carbenicillin (50 $\mu \mathrm{g}$ $\left.\mathrm{mL}^{-1}\right)$ and chloramphenicol $\left(30 \mu \mathrm{g} \mathrm{mL}^{-1}\right)$ were used. $\mathrm{pET} 19 \mathrm{~b}$ encodes the resistance gene for ampicillin, however carbenicillin was used for selection, due to its higher stability. Agar plates were incubated overnight at $37^{\circ} \mathrm{C}$, forming single colonies of bacteria bearing the plasmid encoding the recombinant protein.

\section{Colony PCR reaction}

The PCR reactions with a total volume of $20 \mu \mathrm{L}$ consisted of $10 \mu \mathrm{L}$ Dream Tag Green Master Mix (ThermoFischer), $1 \mu \mathrm{M}$ each of the primers 
(Table 3), one colony of DNA template and $8 \mu \mathrm{L}$ of $\mathrm{ddH}_{2} \mathrm{O}$. The PCR cycles were initiated at $95^{\circ} \mathrm{C}$ for $3 \mathrm{~min}$ to denature the template DNA, followed by 40 amplification cycles. Each amplification cycle consisted of $95^{\circ} \mathrm{C}$ for $3 \mathrm{~min}, 57^{\circ} \mathrm{C}$ for $30 \mathrm{~s}$ and $72 \mathrm{C}$ for $1 \mathrm{~min} 30 \mathrm{sec}$. The PCR cycles were finished with a final extension step at $72^{\circ} \mathrm{C}$ for $15 \mathrm{~min}$. The PCR reactions were analyzed by agarose gel electrophoresis. Presence of the amplified $\sim 1500$ bp product indicated colonies where insertion of the gene was successful.

\section{Expression of the recombinant KkPAL}

The recombinant KKPAL carrying $N$-terminal (His) ${ }_{10}$-tag was overexpressed in E. coli host cells Rosetta(DE3)pLysS. For the expression step, a colony of the transformed plasmid was grown overnight at $37^{\circ} \mathrm{C}$ in $50 \mathrm{~mL}$ of Luria-Bertani (LB) medium containing carbenicillin $\left(50 \mu \mathrm{g} \mathrm{mL}^{-1}\right)$ and chloramphenicol $\left(30 \mu \mathrm{g} \mathrm{mL}^{-1}\right)$. A $0.5 \mathrm{~L}$ of LB medium was inoculated with $1 \mathrm{v} / \mathrm{v} \%$ of the overnight culture and grown at $37^{\circ} \mathrm{C}$ until the optical density at $600 \mathrm{~nm}\left(\mathrm{OD}_{600}\right)$ reached 0.4 , after which the temperature was reduced to 20,25 and $30^{\circ} \mathrm{C}$. To induce protein production varying concentrations of IPTG was added to the cells at $\mathrm{OD}_{600}$ of $0.6-0.7$. In the expression phase the culture was shaken at $180 \mathrm{rpm}$ for $16 \mathrm{~h}$.

\section{Purification of KkPAL}

All protein purification steps were performed at $4 \mathrm{C}$. Cells were harvested by centrifugation $(25 \mathrm{~min}, 5000 \times \mathrm{g})$ and resuspended in $50 \mathrm{~mL}$ lysis buffer (150 mM NaCl, $50 \mathrm{mM}$ TRIS (2-amino-2-(hydroxymethyl)propane1,3-diol) pH 7.5) supplemented with DNAse, RNAse, Lysosyme and EDTAfree protease-inhibitor cocktail. Further, the cells were lysed by sonication and cell debris was removed by centrifugation (12000×g, $30 \mathrm{~min}$ ).

The His-tagged KkPAL was separated from other proteins in the supernatant by Ni-NTA-agarose column. After loading the sample, the column was washed with low salt buffer, (50 mM HEPES (4-)(2hydroxyethyl)piperazine-1-ethanesulfonic acid), $30 \mathrm{mM} \mathrm{KCl} \mathrm{pH} 7.54 \mathrm{~V}$; V= resin volume) high salt buffer (50 mM HEPES, $300 \mathrm{mM} \mathrm{KCl} \mathrm{pH} \mathrm{7.5,} \mathrm{2V),}$ and low salt buffer $(2-4 \mathrm{~V})$ again. The low salt buffer supplemented with 25 $\mathrm{mM}$ imidazole removed the non-specifically bound contaminating proteins. Low salt buffer supplemented with varying amounts (between $250-500 \mathrm{mM}$ ) imidazole eluted the KkPAL from the column.

The resulting eluate was dialyzed against $100 \mathrm{mM}$ TRIS-buffer $(\mathrm{pH}$ 8.0) for $5 \mathrm{~h}$ at $4 \mathrm{C}$. The purity of the resulting fractions was verified by SDS- 
A. VARGA, Z. BATA, P. CSUKA, D. M. BORDEA, B. G. VÉRTESSY, A. MARCOVICI, F. D. IRIMIE,

L. POPPE, L. C. BENCZE

PAGE analysis on a $12 \%$ SDS-PAGE. After dialysis the fractions containing purified protein were concentrated by centrifugal ultrafiltration with Amicon filter units. The concentration of the purified protein was determined by the Bradford method.

\section{Enzyme activity measurements}

Elimination reactions. Activity of KkPAL in the ammonia elimination reaction was determined spectrophotometrically by monitoring the formation of the conjugated acrylic acid product. The measurements were performed at $30 \mathrm{C}$ for $5 \mathrm{~min}$ with $5 \mathrm{mM}$ L-phenylalanine, in the presence of $0.3 \mu \mathrm{M}$ enzyme in $0.1 \mathrm{M}$ TRIS-buffer $(\mathrm{pH}$ 8.5). Phenylalanine ammonialyase activity was determined by measuring the formation of $(E)$-cinnamic acid at $290 \mathrm{~nm}$ for $10 \mathrm{~min}$, using quartz cuvettes of $1 \mathrm{~mL}$. Histidine ammonia-lyase activity was determined as the rate of urocanate formation measured spectrophotometrically at $277 \mathrm{~nm}$. The conversion of L-tyrosine to $p$-coumarate followed at $310 \mathrm{~nm}$, determined the tyrosine ammonia-lyase acitvity. Tryptophan ammonia-lyase activity was measured by the rate of indole 3-acrylic acid formation at $315 \mathrm{~nm}$.

Addition reactions. Into the solution of $(E)$-cinnamic acid $(5 \mathrm{mM})$ in 6 $\mathrm{M} \mathrm{NH}_{3}, \mathrm{pH} 10$ (adjusted with $\mathrm{CO}_{2}$ ), KkPAL or PCPAL $(0.6 \mu \mathrm{M})$ was added and the reaction mixtures were shaken at $300 \mathrm{rpm}$, at $30^{\circ} \mathrm{C}$. After $16 \mathrm{~h}$ samples $(50 \mu \mathrm{L})$ were taken from the enzymatic reaction mixtures, quenched by adding an equal volume of $\mathrm{MeOH}$, vortexed and centrifuged (13000 rpm, $2 \mathrm{~min}$ ). The supernatant was filtered through a $0.22 \mu \mathrm{m}$ membrane filter and used directly for HPLC analysis.

Conversions were determined on Phenomenex Gemini NX-C-18 column, using as mobile phase: $\mathrm{NH}_{4} \mathrm{OH}$ buffer $(0.1 \mathrm{M}, \mathrm{pH}$ 8.5): $\mathrm{MeOH}$ 90:10 to $61: 39$ in $12 \mathrm{~min}$ and $1 \mathrm{~mL} \mathrm{~min}^{-1}$ flow rate. Conversions were calculated from peak area integrations with use of appropriate response factors. [25]

\section{Thermal stability assay}

The thermal stability of the enzyme was determined by nanoDSF. The capillaries were filled with the $0.125 \mathrm{mg} \mathrm{mL}^{-1}(2 \mu \mathrm{M}) \mathrm{KkPAL}$ in $100 \mathrm{mM}$ TRIS-buffer $\mathrm{pH} 8.5$ and placed onto the capillary tray of the Prometheus NT.48, NanoTemper Technologies. Melting curves were measured by heating the samples by $1^{\circ} \mathrm{C} \mathrm{min} \mathrm{m}^{-1}$ increment from $20^{\circ} \mathrm{C}$ to $95^{\circ} \mathrm{C}$. 


\section{ACKNOWLEDGMENTS}

Financial support for project NEMSyB, ID P37_273, Cod MySMIS 103413 funded by the Romanian Ministry for European Funds, through the National Authority for Scientific Research and Innovation (ANCSI) and cofunded by the European Regional Development Fund, Competitiveness Operational Program 2014-2020 (POC), Priority axis 1, Action 1.1 is gratefully acknowledged. LCB thanks for the financial support from the Romanian National Authority for Scientific Research and Innovation, CNCS-UEFISCDI, project number PN-II-RU-TE-2014-4-1668. BGV and LP thank the support from COST Action CM1303 (SysBiocat).

\section{REFERENCES}

[1] B. M. Nestl, S. C. Hammer, B. A. Nebel, B. Hauer, Angewandte Chemie, International Edition 2014, 53, 3070-3095.

[2] J. L. Barredo, Microbial Enzymes and Biotransformations. 2005, Humana Press, Totowa.

[3] D. S. Hodgins, Journal of Biological Chemistry 1971, 246, 2977-2985.

[4] M. Petersen, J. Hans, U. Matern in Annual Plant Reviews, 2nd ed., Vol. 40, Biochemistry of Plant Secondary Metabolism (Ed.: M. Wink), Wiley-Blackwell, 2010, 182-257.

[5] L. Feng, U. Wanninayake, S. Strom, J. Geiger, K. D. Walker, Biochemistry 2011, 50, 2919-2930.

[6] a) S. D. Christenson, W. Liu, M. D. Toney, B. Shen, Journal of the American Chemical Society 2003, 125, 6062-6063; b) C. V. Christianson, T. J. Montavon, S. G. Van Lanen, B. Shen, S. D. Bruner, Biochemistry 2007, 46, 7205-7214.

[7] J. A. Kyndt, T. E. Meyer, M. A. Cusanovich, J. J. Van Beeumen, FEBS Letters 2002, 512, 240-244.

[8] a) L. Givot, T. A. Smith, R. H. Abeles, Journal of Biological Chemistry 1969, 244, 6341-6353; b) R. B. Wickner, Journal of Biological Chemistry 1969, 244, $6550-6552$.

[9] T. F. Schwede, J. Rétey, G. E. Schulz, Biochemistry 1999, 38, 5355-5361.

[10] L. Poppe, Cs. Paizs, K. Kovács, F.D. Irimie, B.G. Vértessy in Methods in Molecular Biology, Vol. 794 (Eds.: L. Pollegioni, S. Servi), 2012, 3-19. Humana Press, Totowa.

[11] F.B.J. van Assema, N. Sereinig (DSM0). WO 2008/031578, 2008 and PCT/EP 2007/007945, 2007.

[12] a) D. Weiser, L.C. Bencze, G. Bánóczi, F. Ender, R. Kiss, E. Kókai, A. Szilágyi, B.G. Vértessy, O. Farkas, C. Paizs, L. Poppe, ChemBioChem, 2015, 16 , 2257-2402; b.) J. H. Bartha-Vári, M. I. Tosa, F.D. Irimie, D. Weiser, Z. 
A. VARGA, Z. BATA, P. CSUKA, D. M. BORDEA, B. G. VÉRTESSY, A. MARCOVICI, F. D. IRIMIE, L. POPPE, L. C. BENCZE

Boros, B. G. Vértessy, Cs. Paizs, L. Poppe, ChemCatChem 2015, 7, 11221128; c.) F. Ender, D. Weiser, B. Nagy, L.C. Bencze, C. Paizs, P. Pálovics, L. Poppe, Journal of Flow Chemistry 2016 , 6, 43-52.

[13] C. Han, J. Sikorski, A. Lapidus, M. Nolan, T. Glavina Del Rio, H. Tice,J. F. Cheng, S. Lucas, F. Chen, A. Copeland, N. Ivanova, K. Mavromatis, G. Ovchinnikova, A. Pati, D. Bruce, L. Goodwin, S. Pitluck, A. Chen, K. Palaniappan, M. Land, L. Hauser, Y. J. Chang, C. D. Jeffries, P. Chain, E. Saunders, T. Brettin, M. Göker, B. J. Tindall, J. Bristow, J. A. Eisen, V. Markowitz, P. Hugenholtz, N. C. Kyrpides, H. P. Klenk, J. C. Detter, Standards in Genomic Sciences, 2009, 1, 226-233.

[14] Söding J, Bioinformatics, 2005, 21, 951-960.

[15] S. Hou, J. H. Saw, K. S. Lee, T. A. Freitas, C. Belisle, Y. Kawarabayasi, S. P. Donachie, A. Pikina, M. Y. Galperin, E. V. Koonin, K.S. Makarova, M. V. Omelchenko, A. Sorokin, Y. I. Wolf, Q. X. Li, Y. S. Keum, S. Campbell, J. Denery, S. Aizawa, S. Shibata, A. Malahoff, M. Alam, Proceedings of the National Academy of Sciences USA, 2004, 101, 18036-18041.

[16] G. V. Louie, M.E. Bowman, M. C. Moffitt, T. J. Baiga, B. S. Moore, J. P. Noel, Chemistry \& Biology 2006, 13, 1327-1338.

[17] F. Baneyx, Current Opinion in Biotechnology, 1999, 10, 411-421.

[18] J. Sambrook, D. W. Russell, Molecular Cloning a Laboratory Manual. 3rd Edition, New York: Cold Spring Harbor Laboratory Press; 2001.

[19] H. M. Sadeghi, M. Rabbani, E. Rismani, F. Moazen, F. Khodabakhsh, K. Dormiani, Y. Khazaei, Research in the Pharmaceutical Science, 2011, 6, 87-92.

[20] R. Y. Li, C. Y. Cheng. Journal Bioscience and Bioengineering, 2009, 107, 512-515.

[21] A. Vera, N. Gonzalez-Montalban, A. Aris, A. Villaverde, Biotechnology and Bioengineering, 2007, 96, 1101-1106.

[22] J. A. Vasina, F. Baneyx, Protein Expression and Purification 1997, 9, 211-218.

[23] J. Crowe, H. Dobeli, R. Gentz, E. Hochuli, D. Stiber, K. Hence, Methods in Molecular Biology, 1994, 31, 371-387.

[24] T. Tanaka, M. Kubota, K. Samizo, Y. Nakajima, M. Hoshino, T. Kohno, E. Wakamatsu, Protein Expression and Purification, 1999, 1, 207-212.

[25] A. Varga, G. Bánóczi, B. Nagy, L. C. Bencze, M. I. Toșa, Á. Gellért, F. D. Irimie, J. Rétey, L. Poppe C. Paizs, RSC Advances, 2016, 6, 56412-56420.

[26] L. C. Bencze, A. Filip, G. Bánóczi, M. I. Toșa, F. D. Irimie, Á. Gellért, L. Poppe, C. Paizs, Organic \& Biomolecular Chemistry, 2017, 15, 3717-3727. 